\title{
Serum Proteomic Signatures of Male Breast Cancer
}

\author{
ELENI ZOGRAFOS ${ }^{1}$, ATHANASIOS K. ANAGNOSTOPOULOS ${ }^{2}$, AGGELIKI PAPADOPOULOU ${ }^{2}$, EVANGELIA \\ LEGAKI $^{1}$, FLORA ZAGOURI ${ }^{3}$, EVANGELOS MARINOS ${ }^{1}$, GEORGE T. TSANGARIS $^{2}$ and MARIA GAZOULI ${ }^{1}$ \\ ${ }^{1}$ Department of Basic Medical Sciences, Laboratory of Biology, School of Medicine, \\ National and Kapodistrian University of Athens, Athens, Greece; \\ ${ }^{2}$ Proteomics Research Unit, Center of Basic Research II, \\ Biomedical Research Foundation of the Academy of Athens, Athens, Greece; \\ ${ }^{3}$ Department of Clinical Therapeutics, Alexandra Hospital, School of Medicine, \\ National and Kapodistrian University of Athens, Athens, Greece
}

\begin{abstract}
Background: To date, the elucidation of serum protein alterations in male breast cancer (MBC) has not been extensively studied, due to the rarity of the disease. Materials and Methods: In the present work, two-dimensional gel electrophoresis (2-DE) and matrix-assisted laser desorption ionization-time of flight mass spectrometry (MALDI-TOF MS) were employed to detect differences in serum protein expression between patients with $M B C$ and healthy controls. Results: A panel of differentially expressed serum proteins was identified, including proteins involved in the regulation of the cell cycle [e.g. cell division cycle 7-related protein kinase $(C D C 7)]$, in mitochondrial function [e.g. mitochondrial aldehyde dehydrogenase ( $A L D H 2)$ and dimethyladenosine transferase 1 (TFB1M)], in lipid metabolism and transport [e.g. apolipoprotein A-I (APOAI) and E (APOE)], in apoptosis and immune response [e.g. CD5 antigen-like $(C D 5 L)$, clusterin (CLUS) and $C-C$ motif chemokine 14 (CCL14)], in transcription (e.g. protein SSX3 and signal transducer and activator of transcription 3 (STAT3)], in invasion and metastasis (e.g. alpha-2-HS-glycoprotein (FETUA)], in estrogen synthesis [aromatase (CYP19A1)] and other diverse biological roles [e.g. actin-related protein $2 / 3$ complex subunit 4 (ARPC4), dual specificity mitogen-activated protein kinase kinase 4 (MP2K4), ectoderm-neural cortex protein 1 (ENC1), and matrix metalloproteinase-27
\end{abstract}

This article is freely accessible online.

Correspondence to: Maria Gazouli, Ph.D., Assoc. Prof. of Molecular Biology, Dept of Basic Medical Sciences, School of Medicine, National and Kapodistrian University of Athens, Michalakopoulou 176, 11527 Athens, Greece. Tel: +30 2107462231, +30 2107462244, e-mail: mgazouli@med.uoa.gr

Key Words: Male breast cancer, proteomics, mass spectrometry, serum biomarkers.
(MMP27)]. Conclusion: These findings provide valuable insight into the distinct clinicopathological features of $M B C$ and indicate that select serum proteomic markers may help improve MBC management.

Male breast cancer (MBC) is an uncommon malignancy accounting for fewer than $1 \%$ of all male cancers (1), with an incidence of less than one per 100,000 men-years, which is considerably low compared to female breast cancer (FBC) (2). The heterogeneity of breast cancer is well established. Recent advances in genomic technologies have helped researchers expand their insight into the genetic basis of cancer and have provided them with an important tool for the discovery of novel biomarkers (3). Still, we presently know that the genomic approach has its limitations; gene- or transcript-level analysis may not directly reflect cellular functions, due to key biological mechanisms such as alternative splicing and posttranslational modification of proteins (4).

It is currently considered that in contrast to the genome, the proteome itself reveals a more dynamic state of the cell, since changes in the mutational landscape of the genome are translated into an aberrantly regulated proteome (5). Therefore, proteomic technologies, including mass spectrometry-generated data, aim to identify variations in proteins circulating in the blood which can serve as a less invasive alternative to histopathological assessment. The proteomic approach may have the ability to transform the clinical management of disease and discover serum biomarkers that can be integrated into personalized patient care (6).

Data on protein alterations in male breast carcinogenesis is scarce, due to the rarity of the disease. It is interesting that although some studies have identified similarities between breast cancer in men and in postmenopausal women (7), there is increasing evidence suggesting that the disease in men differs both causally, as well as in the clinicopathological characteristics and in outcomes (8). Consequently, data on proteomics in women should not be extrapolated to men due 
to the fundamental differences between the two entities. There is an immense need for personalized management of $\mathrm{MBC}$; in consequence, a panel of indicators obtained by a simple blood withdrawal, a so-called liquid biopsy, would represent a significant advance.

To the best of our knowledge, there is very limited information regarding proteomic MBC biomarkers circulating in human serum, which represents an attractive, easily-accessible source for biomarker discovery. In the current study, two-dimensional gel electrophoresis (2-DE) separation and matrix-assisted laser desorption/ionization time-of-flight mass spectrometric (MALDI-TOF-MS) analysis were employed to monitor differences in serum protein expression between patients with MBC and healthy individuals. Our aim was to identify a panel of candidate proteins that could be used to better understand $\mathrm{MBC}$ pathology, in order to improve MBC management and to advance oncological medical care.

\section{Materials and Methods}

Patients. Eleven male patients with sporadic breast cancer (MBC) and eight healthy individuals, who were attending the First Propaedeutic Surgical Department at Hippokration General Hospital and the Department of Clinical Therapeutics at the Alexandra Hospital in Athens, Greece, were enrolled in this study. The control group consisted of age-matched healthy individuals, admitted for a routine annual physical examination, who had no family history of malignancy. Participation was voluntary and informed consent was provided by each participant. The study was approved by the Ethical Committees of the participating hospitals (approval number ES66/28-5-2015). MBC was diagnosed based on a combination of standard clinical, radiological and histological criteria (9). The main demographic and clinical characteristics of the MBC patients are presented in Table I.

Proteomic analysis. A blood sample was collected from each patient at the time of diagnosis. Following centrifugation, serum was collected and stored at $-80^{\circ} \mathrm{C}$ until use. The protein concentration was determined with a Bioanalyzer system (Agilent Technologies Inc., Waldbornn, Germany), using Protein 200 plus kit (Agilent Technologies Inc.). 2-DE was performed as previously described (10). Gel images were scanned in a GS-800 Calibrated Densitometer (Bio-Rad, Hercules, CA, USA) and images were stored in digital format for further analysis.

Image analysis. Protein spots from all gels analyzed were detected, aligned, matched and quantified using PD-Quest v8.0 image processing software (Bio-Rad) according to the manufacturer's instructions. Manual inspection of the spots was carried out to verify the accuracy of matching. Spot volume was used to quantify protein expression. Normalization of each individual spot was performed according to the total quantity of the valid spots in each gel, after subtraction of the background values. Optical density (O.D.) level (\%) of each protein from the control and MBC groups was determined separately and calculated as the sum of the percentage volume of all spots from all gels containing the same protein.
Table I. Clinical characteristics of patients with male breast cancer.

\begin{tabular}{|c|c|}
\hline Variable & $\mathrm{N}(\%)$ \\
\hline \multicolumn{2}{|l|}{ Age at diagnosis } \\
\hline$\leq 50$ Years & $2(18.2)$ \\
\hline$>50$ Years & $9(81.8)$ \\
\hline \multicolumn{2}{|l|}{ Race } \\
\hline Caucasian & $11(100.0)$ \\
\hline Other & $0(0)$ \\
\hline \multicolumn{2}{|l|}{ Tumor size } \\
\hline $\mathrm{T} 1$ & $5(45.5)$ \\
\hline $\mathrm{T} 2$ & $4(36.4)$ \\
\hline $\mathrm{T} 3$ & $1(9.1)$ \\
\hline $\mathrm{Tx}$ & $1(9.1)$ \\
\hline \multicolumn{2}{|l|}{ Tumor type and grade } \\
\hline Ductal, I & $2(18.9)$ \\
\hline Ductal, II & $6(54.6)$ \\
\hline Ductal, III & $3(27.3)$ \\
\hline Lobular & $0(0)$ \\
\hline \multicolumn{2}{|l|}{ Lymph nodes } \\
\hline No & $8(72.7)$ \\
\hline N1 & $2(18.2)$ \\
\hline $\mathrm{N} 2$ & $0(0)$ \\
\hline N3 & $0(0)$ \\
\hline $\mathrm{Nx}$ & $1(9.1)$ \\
\hline \multicolumn{2}{|l|}{ ER } \\
\hline Positive & $10(90.9)$ \\
\hline Negative & $1(9.1)$ \\
\hline \multicolumn{2}{|l|}{ PR } \\
\hline Positive & $9(81.9)$ \\
\hline Negative & $2(18.2)$ \\
\hline \multicolumn{2}{|l|}{ HER 2/neu } \\
\hline Positive & $1(9.1)$ \\
\hline Negative & $10(90.9)$ \\
\hline \multicolumn{2}{|l|}{ Ki-67 } \\
\hline Low $(<15 \%)$ & $7(63.6)$ \\
\hline Moderate (16-30\%) & $4(36.4)$ \\
\hline High $(>30 \%)$ & $0(0)$ \\
\hline
\end{tabular}

ER: Estrogen receptor; PR: progesterone receptor; HER2/neu: human epidermal growth factor receptor 2; Ki-67: proliferation marker protein Ki-67.

Selection of protein spots for MS identification was based upon O.D. alterations observed between the two groups. A minimum of 1.5-fold change in the expression level was used as a selection criterion.

Protein identification by MALDI-TOF-MS. For MALDI-TOF-MS analysis, gel spots of interest were manually annotated using Melanie 4.02 software and excised from 2-DE gels using Proteiner SPII (Bruker Daltonics, Bremen, Germany). Gel pieces were then placed into 96-well microtiter plates, destained with $180 \mu \mathrm{l}$ of $30 \%$ acetonitrile $(\mathrm{ACN})$ in $50 \mathrm{mM}$ ammonium bicarbonate and dried in a speed vacuum concentrator (MaxiDry Plus; Heto, Allered, Denmark). In-gel digestion was performed with $0.01 \mu \mathrm{g} / \mu \mathrm{l}$ trypsin (Roche Diagnostics, Basel, Switzerland) for $16 \mathrm{~h}$ at room temperature. Next, $10 \mu \mathrm{l}$ of $50 \% \mathrm{ACN}$ containing $0.1 \%$ trifluoroacetic acid, were added to each dried gel piece and tryptic digested peptides were extracted. Tryptic peptide mixtures $(1 \mu \mathrm{l})$ were applied on an anchor chip MALDI plate mixed with $1 \mu \mathrm{l}$ of matrix solution, consisting of $0.08 \%$ 
--cyano-4-hydroxycinnamic acid (Sigma-Aldrich, St. Louis, MO USA) and internal standard peptides des-Arg-bradykinin (904.4681 Da; Sigma-Aldrich) and adrenocorticotropic hormone fragment 1839 (2465.1989 Da; Sigma-Aldrich) in 50\% distilled water, 50\% ACN and $0.1 \%$ trifluoroacetic acid. Peptide mixtures were analyzed in a MALDI-TOF MS as described by Vaiopoulou et al. (10). Peptide masses were compared with the theoretical peptide masses of all available proteins from Homo sapiens in the SWISS-PROT and TREmBL databases. Stringent criteria were used for protein identification with a maximum allowed mass error of $25 \mathrm{ppm}$ and a minimum of four matching peptides. probability score with $p<0.05$ was used as the criterion for affirmative protein identification. Monoisotopic masses were used, and one missed trypsin-cleavage site was calculated for proteolytic products. Search parameters included potential residue mass modification for carbamidomethylation and oxidation. Any redundancy of proteins that appeared in the database under different names and accession numbers was eliminated. If more than one protein was identified under one spot, the single protein member with the highest protein score was singled out from the multi-protein family.

Western blot analysis. Total proteins $(10 \mu \mathrm{g})$ of control and MBC serum samples were separated by $10 \%$ sodium dodecyl sulfate polyacrylamide gel electrophoresis (Mini-PROTEAN ${ }^{\circledR}$ TGX $^{\mathrm{TM}}$ Precast Protein Gels; Bio-Rad) under reducing conditions and electroblotted to Porablot polyvinylidene difluoride membranes (Macherey-Nagel, Düren, Germany). After blocking with 5\% nonfat dried milk in a solution of $20 \mathrm{mM}$ Tris/pH 7.6, $137 \mathrm{mM} \mathrm{NaCl}$ and $0.1 \%$ Tween 20 (TBST) for $1 \mathrm{~h}$ at room temperature, membranes were washed with TBST and incubated overnight at $4^{\circ} \mathrm{C}$ with primary antibody against apolipoprotein E (APOE; dilution 1:600; Santa Cruz Biotechnology, Dallas, TX, USA). Next, membranes were washed with TBST and incubated with a goat anti-mouse horseradish peroxidase-conjugated secondary antibody (A00160, dilution 1:1000; GenScript Biotech Corp., Piscataway, NJ, USA). After a final wash with TBST solution, proteins were detected by ECL western blotting detection system (Thermo Scientific, Rockford, IL, USA). Western blots were scanned with a GS-800 calibrated densitometer (Bio-Rad). Band quantification was performed with Quantity One image processing software (Bio-Rad). Human IgG protein was used as an internal control to ensure equal sample loading (sc-69786, dilution 1:400; Santa Cruz Biotechnology).

Enzyme-linked immunosorbent assay (ELISA). Aromatase ELISA kit was purchased from Fine Biotech (EH2665; Fine Test, Wuhan, Hubei, P. R. China). The assay was performed following the kit instructions. Plates were read on a Multiskan ${ }^{\circledR}$ GO Microplate Reader (Thermo Fisher, Basingstoke, UK) with appropriate baseline correction. ELISA values were normalized for each 96-well plate, using standard solutions provided in the kit. The samples were not diluted, since the target protein concentration was very low $(\leq 0.156 \mathrm{ng} / \mathrm{ml})$.

Pathway analysis. Functional relationships analysis of the differentially expressed proteins was performed using the STRING v.10 database (Search Tool for the Retrieval of Interacting Genes/Proteins, http://string-db.org). The simplified version of the produced network, which involved both up- and down- regulated proteins, was adopted. The PANTHER database was used to reveal the molecular function and signaling pathway associated with each identified protein (http://panther.appliedbiosystems.com/).
Statistical analysis. To ensure confidence in our experimental approach, we employed an experimental design which involved duplicate 2-DE gels per sample and separate preparations for each replicate sample per experiment. Comparisons were performed between samples (MBC patients versus healthy controls). Mean densitometric values of all spots corresponding to a specific protein from each group were first checked for normal distribution using unequal variances. Data with normally distributed densitometric values were exported to Microsoft Excel 2016 software (Microsoft Corp., Redmond, WA, USA) and compared with the two pair $t$-test assuming unequal variance. Means of spot intensities for proteins with non-normally distributed values were compared for statistical significance with the Mann-Whitney nonparametric test (GraphPad Instat 3 software; GraphPad Software Inc., La Jolla, CA, USA). Statistical significance (alpha-level) was defined as $p<0.05$. To control the false discovery rate (FDR), individual alpha-levels for each spot were adjusted following the FDR correction procedure.

In western blot and ELISA experiments, protein quantification was performed by three independent experiments for each protein analyzed. Mean optical density for each protein of the control and MBC groups were compared with independent samples $t$-test assuming unequal variances in Microsoft Excel 2016 (Microsoft Corp.). A $p<0.05$ was considered statistically significant.

\section{Results}

Proteomic analysis. In order to detect serum proteins differentially expressed in the serum of patients with MBC and healthy controls, each protein sample was separated by $2-$ DE (Figure 1). Statistical analysis of the resulting 2-DE gels revealed 504 protein spots differentially expressed between the two groups. Two hundred and fifty-two proteins corresponding to the 504 spots were identified since more than one spot was related to the same protein. Table II focuses on the 42 proteins differentially expressed in all samples $(n=11)$ of the patient group, which fulfilled the following requirements: Mascot Score $>40$ and an expression level of $>1.5$ or $<0.5$. This table provides their identities, theoretical pI, molecular weight, MASCOT score, protein coverage, and expression levels as calculated with PDQuest 8.0 software. An expression level $>1.5$ indicates overexpression and that of $<0.5$ shows underexpression. Mascot scores $>40$ indicate identity or extensive homology at the $p<0.05$ level.

Western blot analysis. The differential expression of APOE was further confirmed by western blot analysis using appropriate antibodies for both MBC and control samples. Optical density measurements of the bands revealed that there was a 1.89 -fold increase $(p=0.0017)$ in the amount of APOE in serum collected from patients with MBC compared to healthy controls (Figure 2).

ELISA. Serum aromatase (CYP19A1) concentrations in patients with $\mathrm{MBC}$ and healthy controls were measured using ELISA since CYP19A1 is an endoplasmic reticulum enzyme also detected in the serum. CYP19A1 was similarly 

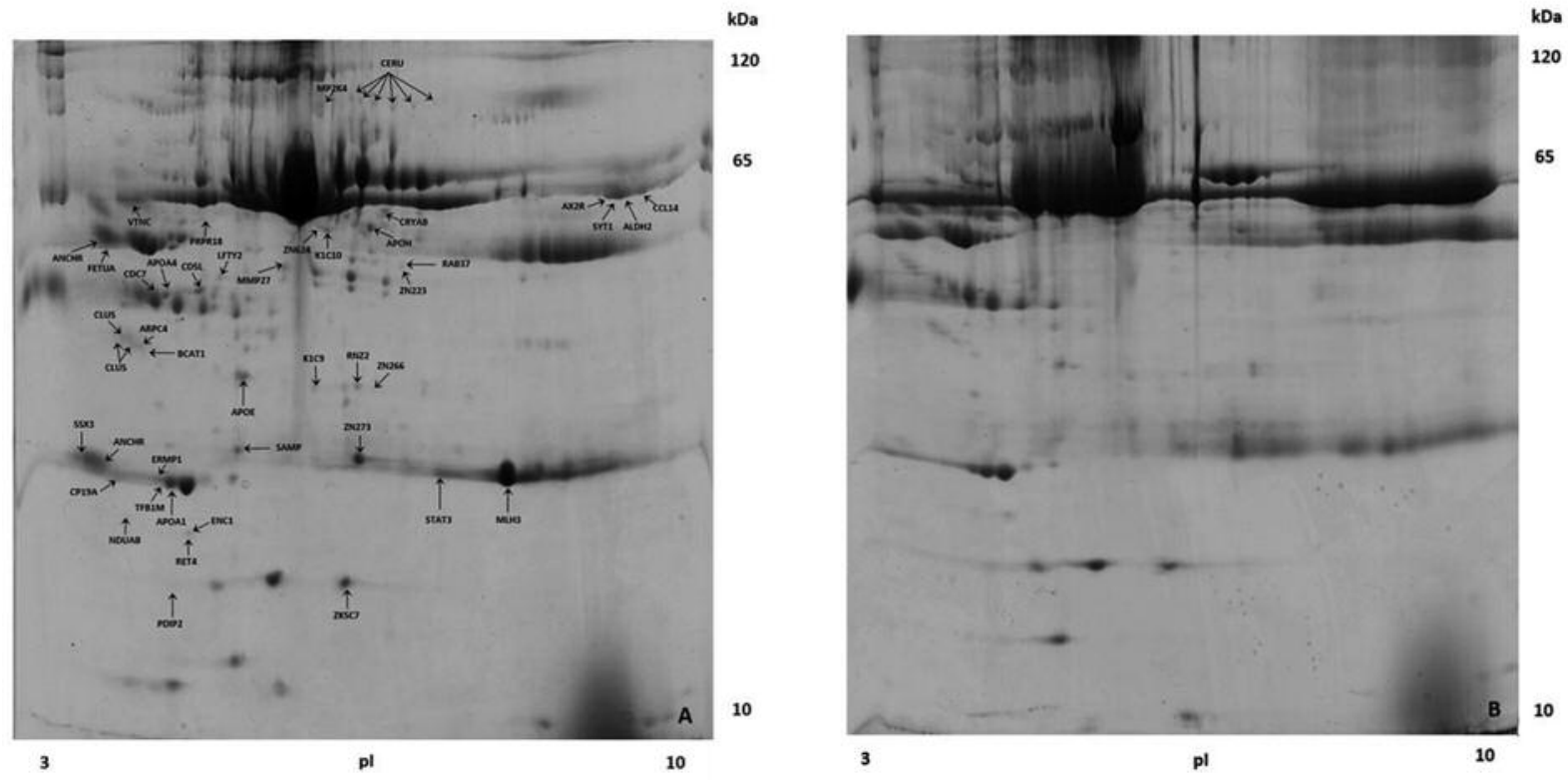

Figure 1. Serum samples from patients with male breast cancer $(A)$ and healthy controls $(B)$ were analyzed by two-dimensional gel electrophoresis $(2-D E)$. The gels were stained with Coomassie blue and protein spots were excised and further analyzed by matrix-assisted laser desorption ionization time-of-flight mass spectrometry, as described in the Materials and Methods section. In the gel images, each spot represents a protein. Comparison of protein profiles revealed proteins differentially expressed between the two groups analyzed (arrows). Protein abbreviations used are presented in Table II.

expressed among patients with MBC and healthy individuals. The mean serum CYP19A1 level was $0.189 \pm 0.115 \mathrm{ng} / \mathrm{ml}$ for patients with $\mathrm{MBC}$ and $0.193 \pm 0.156 \mathrm{ng} / \mathrm{ml}$ for healthy controls $(p=0.95)$.

Pathway analysis. The pathways which engage differentially expressed proteins identified in our samples were studied using the STRING database (Figure 3). For this interpretation, an analysis of 42 proteins was performed using the PANTHER classification system, which sorts the proteins into respective groups based on their biological process, and their involvement in different signaling pathways (Figure 4). As presented in Figure 4A, it is of great interest that the three major groups involved molecules related to cellular process $(42.9 \%)$, metabolic process proteins $(35.7 \%)$, and members of the response to stimulus process, factors that are known to be aberrant in cancer. Regarding the PANTHER pathway analysis, as illustrated in Figure 4B, six main pathways were identified. Specifically, $8.3 \%$ of proteins identified as being overexpressed in the MBC samples corresponded to proteins found in the angiogenesis pathway, $8.3 \%$ in the cholecystokinin receptor (CCKR) signaling map, $5.6 \%$ in the RAS pathway, $5.6 \%$ in the gonadotropin-releasing hormone receptor pathway, $5.6 \%$ in the epidermal growth factor receptor (EGFR) signaling pathway, and $5.6 \%$ in the inflammation mediated by chemokine and cytokine signaling pathway.

\section{Discussion}

We attempted to characterize the serum protein profile of patients with MBC using the MALDI-TOF-MS technique. According to our results, several proteins were differentially expressed in patients with MBC compared to controls. Among the proteins identified in our study, 38 were found to be upregulated in all samples of the MBC group. Additionally, we found that spots corresponding to four proteins were detected only in patients with MBC. These results indicate that select serum proteomic markers might help elucidate the differences between patients with MBC and healthy individuals.

Very limited studies on breast cancer have focused on the male population and there is a lack of information regarding validated proteomic biomarkers in patients with MBC. Most proteomic studies refer to women and have identified possible biomarkers $(11,12)$, but few have been validated so as to achieve clinical application (13). Regarding MBC, as far as we are aware of, only one single study has been performed using MS-based technologies. Chahed et al. performed a thorough proteomic study of protein-expression alterations in MBC tissues (14), where overexpression of multiple proteins in male breast tumors was identified. To our knowledge, however, there are no studies attempting to mine the entire serum proteome of patients with $\mathrm{MBC}$, as a less invasive approach for the discovery of candidate biomarkers. 

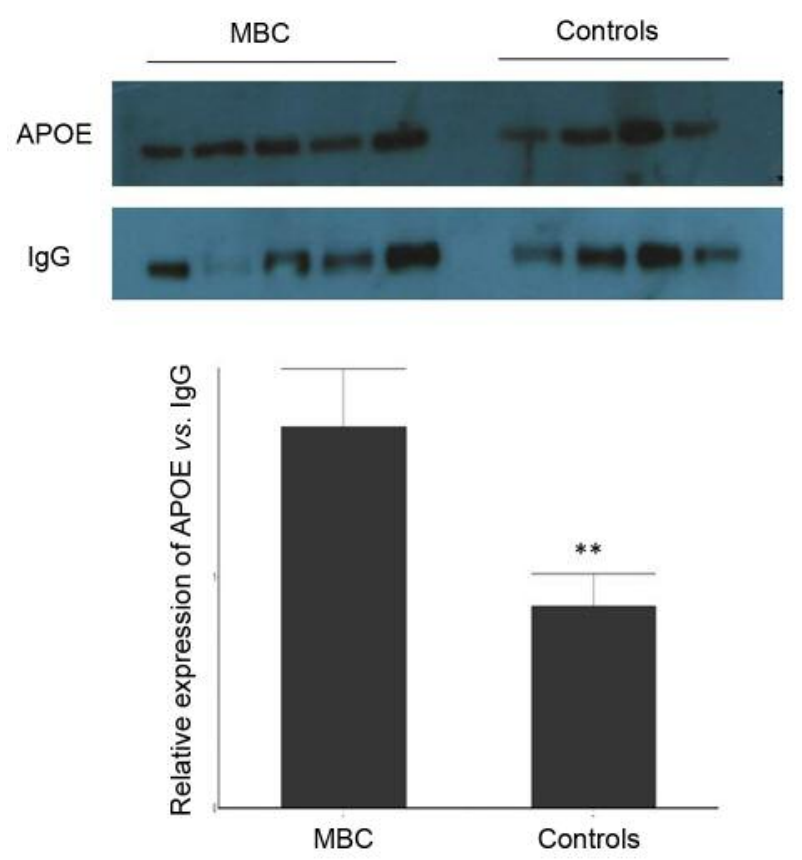

Figure 2. Confirmation of the differential expression of apolipoprotein E by western blot analysis. Quantification of protein content was performed using scanning densitometry. Each bar represents the mean optical density $\pm S D$ of three independent experiments. **Differences were significant at $p<0.0017$.

Differential expression of several proteins that carry out diverse biological roles was identified. Of these, we focused our discussion on the most clinically important ones. Concerning proteins involved in the regulation of the cell cycle, cell division cycle 7-related protein kinase (CDC7) is implicated in cell division, cell-cycle checkpoint mechanisms, and cancer progression. Our findings, suggest that this protein is overexpressed in $\mathrm{MBC}$, and are in line with previous results on FBC (15). It has also been reported that high level expression of CDC7 is linked to unfavorable prognosis (16). Interestingly, a phase 1 study investigating a CDC7 inhibitor (TAK-931) in patients with advanced non-hematological malignancies is currently ongoing (17).

Aberrant expression of several mitochondrial proteins was also observed. Mitochondrial aldehyde dehydrogenase (ALDH2) belongs to the ALDH family of enzymes. Recent evidence reveals ALDH's potential role as a cancer stem cell marker (18). Consequently, high expression levels of ALDH directly correlate with poor clinical outcome in patients with breast cancer, since cancer stem cell s have been implicated in breast tumor initiation, metastatic spread and recurrence (19). Additionally, our results showed overexpression of mitochondrial dimethyladenosine transferase 1 (TFB1M), which is consistent with previous findings revealing elevated

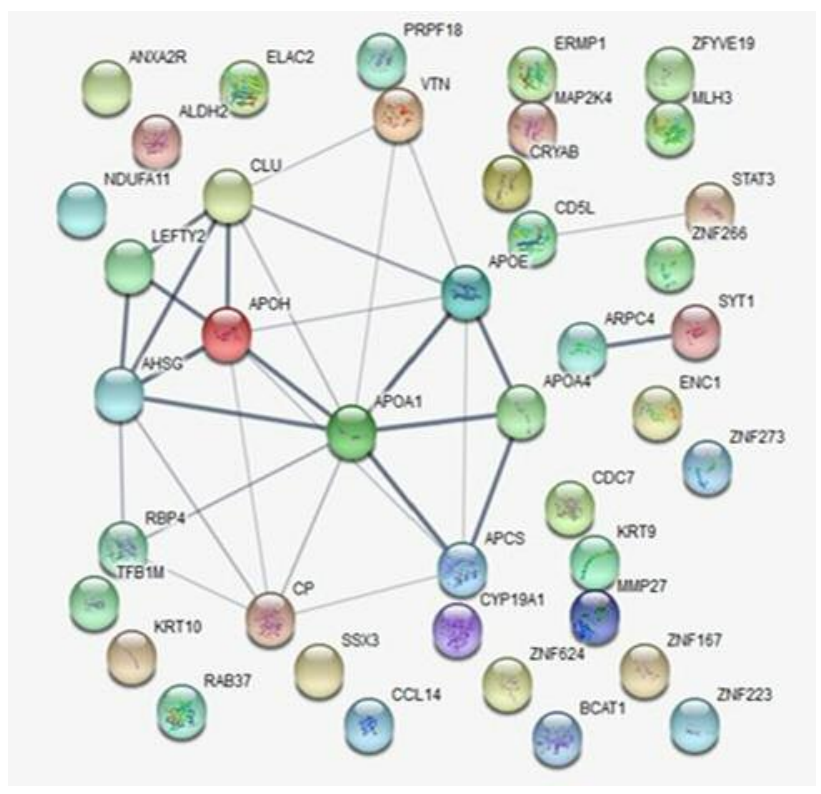

Figure 3. The figure depicts the interactions of the proteins identified as being differentially expressed in our study. Thicker network lines demonstrate stronger protein relation as well as neighboring positions. Protein abbreviations used are presented in Table II.

expression of transcription factors associated with mitochondrial biogenesis in FBC, including TFB1M (20).

In our study, proteins involved in lipid metabolism and transport were found to be up-regulated in the MBC group, including proteins with potential clinical significance, namely apolipoprotein A-I (APOA1) and APOE. This comes as no surprise since research has shown that the dysmetabolism of lipids or lipoproteins circulating in the blood may influence carcinogenesis through inflammation and oxidative stress pathways (21). The role of APOA1 in cancer is under investigation. Results of previous studies on the relationship between APOA1 and breast cancer are mixed. High levels of APOA1 were associated with higher incidence rates of breast cancer (22), while another study indicated an inverse correlation between APOA1 levels and breast malignancies (23). Serum APOE may play diverse roles in several biological processes and reports show that it is up-regulated in various malignancies, including breast cancer, possibly acting as a defense mechanism $(24,25)$. Xu et al. not only showed that serum APOE levels were elevated in patients with breast cancer compared to healthy controls, which is in line with our own results, but also that patients with high serum APOE levels had a worse prognosis, indicating that serum APOE could be an independent prognostic variable for breast cancer (26). All these findings suggest that serum APOE may serve as a non-invasive serological biomarker for distinguishing patients with breast 
Table II. Proteins differentially present in the serum of patients with male breast cancer (MBC) and healthy individuals. Only proteins identified/present in all samples $(n=11)$ with a MASCOT Score $>40$ and an expression level of $>1.5$ or $<0.5$ are included in the table, consisting initially of 252 entries.

\begin{tabular}{|c|c|c|c|c|c|c|}
\hline Full protein name & Abbreviation & Protein MW & $\mathrm{pI}$ & $\begin{array}{c}\text { MASCOT } \\
\text { Score }\end{array}$ & Coverage & $\begin{array}{l}\text { Mean } \\
\text { ratio* }\end{array}$ \\
\hline Abscission/NoCut checkpoint regulator & ANCHR & 52,427 & 5.47 & 40 & 14 & 5.42 \\
\hline Aldehyde dehydrogenase, mitochondrial & ALDH2 & 56,859 & 6.76 & 40 & 17 & 1.89 \\
\hline Alpha-2-HS-glycoprotein & FETUA & 40,098 & 5.40 & 47 & 17 & 9.91 \\
\hline Alpha-crystallin B chain & CRYAB & 20,146 & 6.92 & 41 & 27 & 2.77 \\
\hline Annexin-2 receptor & AX2R & 22,181 & 4.73 & 42 & 26 & 2.42 \\
\hline Apolipoprotein A-I & APOA1 & 30,759 & 5.50 & 133 & 43 & 2.46 \\
\hline Apolipoprotein A-IV & APOA4 & 45,371 & 5.20 & 209 & 45 & 4.32 \\
\hline Apolipoprotein E & APOE & 36,246 & 5.50 & 93 & 28 & 2.92 \\
\hline Aromatase & CYP19A1 & 58,358 & 7.84 & 43 & 17 & 1.55 \\
\hline Beta-2-glycoprotein 1 & $\mathrm{APOH}$ & 39,584 & 9.50 & 58 & 19 & 2.25 \\
\hline Branched-chain-amino-acid aminotransferase, cytosolic & BCAT1 & 43,509 & 5.00 & 40 & 9 & 2.91 \\
\hline C-C motif chemokine 14 & CCL14 & 10,899 & 9.78 & 40 & 26 & 1.52 \\
\hline CD5 antigen-like & CD5L & 39,603 & 5.20 & 79 & 15 & 3.66 \\
\hline Cell division cycle 7-related protein kinase & $\mathrm{CDC} 7$ & 64,646 & 9.77 & 41 & 13 & 4.32 \\
\hline Ceruloplasmin & CERU & 12,2983 & 5.40 & 74 & 13 & 4.28 \\
\hline Clusterin & CLUS & 53,031 & 5.90 & 50 & 11 & 2.36 \\
\hline Dimethyladenosine transferase 1 , mitochondrial & TFB1M & 39,860 & 10.05 & 52 & 28 & 2.39 \\
\hline DNA mismatch repair protein Mlh3 & MLH3 & 16,6059 & 6.30 & 41 & 10 & 1.88 \\
\hline Endoplasmic reticulum metallopeptidase 1 & ERMP1 & 10,1023 & 7.46 & 41 & 7 & 2.09 \\
\hline Keratin, type I cytoskeletal 10 & $\mathrm{~K} 1 \mathrm{C} 10$ & 59,020 & 5.00 & 67 & 19 & 2.51 \\
\hline Keratin, type I cytoskeletal 9 & $\mathrm{~K} 1 \mathrm{C} 9$ & 62,255 & 5.00 & 72 & 22 & 3.18 \\
\hline Left-right determination factor 2 & LFTY2 & 41,407 & 10.20 & 40 & 15 & 1.80 \\
\hline NADH dehydrogenase [ubiquinone] 1 alpha subcomplex subunit 11 & NDUAB & 15,071 & 9.80 & 40 & 31 & 2.47 \\
\hline Polymerase delta-interacting protein 2 & PDIP2 & 42,235 & 9.50 & 49 & 18 & 4.06 \\
\hline Pre-mRNA-splicing factor 18 & PRP18 & 40,006 & 9.00 & 52 & 9 & 21.62 \\
\hline Protein SSX3 & SSX3 & 21,740 & 9.40 & 40 & 23 & 2.46 \\
\hline Ras-related protein Rab-37 & RAB37 & 25,028 & 5.96 & 48 & 36 & 1.90 \\
\hline Retinol-binding protein 4 & RET4 & 23,337 & 5.70 & 67 & 34 & 1.64 \\
\hline Serum amyloid P-component & SAMP & 25,485 & 6.10 & 82 & 26 & 1.61 \\
\hline Signal transducer and activator of transcription 3 & STAT3 & 88,810 & 5.90 & 42 & 15 & 1.88 \\
\hline Synaptotagmin-1 & SYT1 & 47,885 & 9.02 & 41 & 18 & 2.00 \\
\hline Vitronectin & VTNC & 55,069 & 5.50 & 64 & 14 & 6.48 \\
\hline Zinc finger protein 223 & ZN223 & 57,380 & 10.16 & 60 & 13 & 1.80 \\
\hline Zinc finger protein 266 & ZN266 & 64,129 & 10.10 & 47 & 15 & 2.48 \\
\hline Zinc finger protein 273 & ZN273 & 66,868 & 10.54 & 44 & 13 & 8.80 \\
\hline Zinc finger protein 624 & ZN624 & 10,2544 & 10.11 & 44 & 10 & 1.58 \\
\hline Zinc finger protein with KRAB and SCAN domains 7 & ZKSC7 & 86,918 & 7.60 & 51 & 6 & 1.95 \\
\hline Zinc phosphodiesterase ELAC protein 2 & RNZ2 & 93,415 & 9.20 & 40 & 7 & 2.34 \\
\hline Actin-related protein $2 / 3$ complex subunit 4 & ARPC4 & 19,768 & 9.39 & 41 & 27 & MBC only \\
\hline Dual specificity mitogen-activated protein kinase kinase 4 & MP2K4 & 44,716 & 9.10 & 44 & 22 & MBC only \\
\hline Ectoderm-neural cortex protein 1 & ENC1 & 67,285 & 6.43 & 45 & 10 & MBC only \\
\hline Matrix metalloproteinase-27 & MMP27 & 59,330 & 9.40 & 51 & 13 & MBC only \\
\hline
\end{tabular}

MASCOT search score is $-10 \log (p)$, where $p$ is the probability that an observed match is a random event. Scores $>40$ indicate identity or extensive homology at the $p<0.05$ level. *Expression levels were calculated relative to control densities. Expression level $>1.5$ shows overexpression, expression level $<0.5$ indicates underexpression.

cancer from healthy controls, highlighting its potential contribution in clinical practice.

Several of the proteins identified as being overexpressed in serum from patients with MBC seem to have an essential role in the mediation of cancer cell biology, including uncontrolled cell growth, invasion and metastasis. Alpha-2-
HS-glycoprotein (FETUA) is a multifunctional protein contributing to the modulation of many critical signaling pathways such as transforming growth factor beta (27). It has been demonstrated that purified FETUA mediates the adhesion and spreading of breast cancer cells in vitro, via a novel mechanism involving cellular exosomes (28). 
A Biological processes
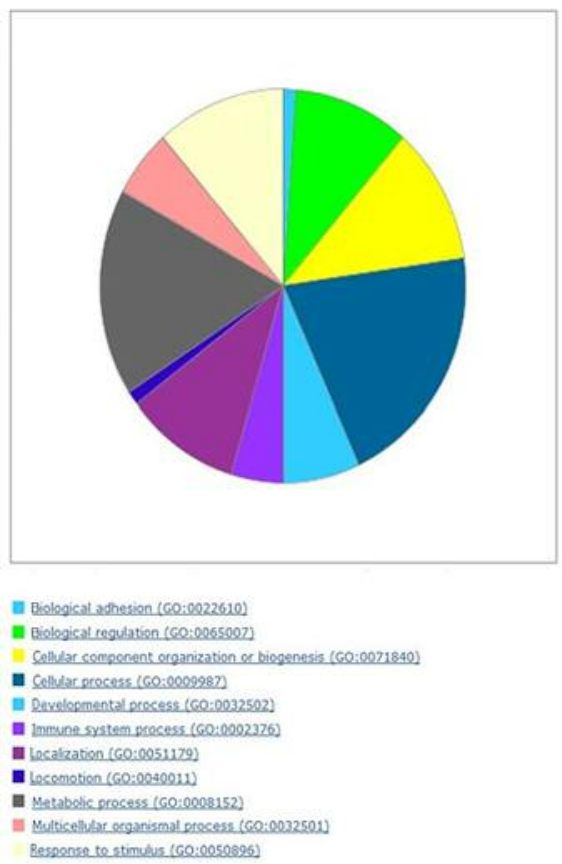

B Pathway analysis

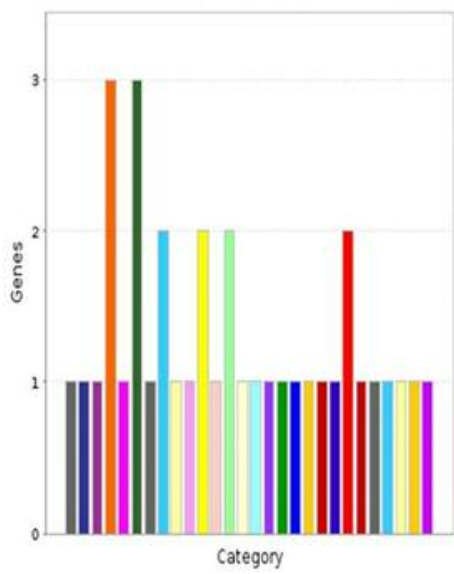

5-Hudroxytrvptarine degredation (p04372)

Alanine biosynthesis (P02724)

Androgen/estrogene/grogesterone biosynthesis (P02727)

Angiogenesis (P0e005)

Apoptosis sionaling pathway (P00006)

a CCKR signaling map (P06959)

- Cytoskeletal regulation by Rho GTPase (P00016)

EGF receptor signaling pathway (P00018)

EAS signaing eathway (P00020)

EGE signaling. oathway (P00021)

Gonadotropin-releasing hormone receptor pathway (P06664)

Huntingten disease (P00029)

Inflammation medared by chemokine and cytokine signaing pathway ( $P 00031$ )

Insuln/IGF pathway-mitogen activated pcotein kinase binase/MAP kinase cascade (P00032)

Integrin signalling oathway (P00034)

Interleukin signaling oathway (P00036)

Isolencine biosynthesis (P02748)

- MKK/STAT signaling pathway (P00038)

III Leucine biosmnthesis (P02749)

- oridative stress response (P00046)

- PDGF signaing pathway (PODOA7)

- Ras Pathway (P04393)

- Smaptic vescicle trafficking (P05734)

TGF-beta signaling pathway (P00052

III Tell receptor sionaling sathway (P00054)

VEGF signaing pathway (PD0056)

1 Valine biosunthesis ( $(202785$ )

D38 MAPK pathway (P05918)

Figure 4. PANTHER analysis. In total, 42 proteins were found to be differentially expressed between male breast cancer samples and healthy controls. A: Classification of these proteins into different groups based on their biological process. B. The different signaling pathway hits of these proteins.

Additionally, FETUA may act as a chemo-attractant for tumor cells along its concentration gradient and promote invasion (29). Our results concerning the aberrant expression of two different cytokeratins, $\mathrm{K} 1 \mathrm{C} 10$ and $\mathrm{K} 1 \mathrm{C} 9$, are consistent with an earlier study that reported the expression of key elements of the epithelial to mesenchymal transition process in breast tumor samples, including several cytokeratin forms and fragments (30).

Aromatase (CYP19A1) is responsible for the transformation of androgen precursors into estrogens. Estrogen receptor expression is highly positive in $>90 \%$ of MBC cases and androgen receptor expression is present in as many as $87.6 \%$ of breast cancer cases in men $(1,31)$, and this may have important therapeutic implications in the follow-up of the disease. Aromatase inhibitors (AIs) are extensively used for treating hormone receptor-positive, postmenopausal women with breast cancer as well as patients with metastatic MBC. However, analyses of male patients show that men do not respond equally well when treated with AIs, while AIs can only be recommended in male patients in conjunction with a luteinizing hormonereleasing hormone agonist (32). In this setting, their use in MBC is not substantiated by data deriving from prospective clinical trials but is based on similarities to postmenopausal FBC. According to our results following MALDI-TOF-MS analysis, serum CYP19A1 protein levels were similar between the two groups. This finding question the extrapolation of data and treatment effects of AIs from clinical studies in women, especially after considering the distinctive molecular and endocrine profile of the disease in men. ELISA assay confirmed our initial results, even though the target protein concentration was very low. The low levels detected may be due to tumor accumulation of these estrogens, since studies in postmenopausal women have shown that the levels of estrogens in breast cancer tissues can be several-fold higher than those in blood (33).

Finally, four proteins were detected only in the MBC group and not in the control samples: actin-related protein 2/3 complex subunit 4 (ARPC4), dual specificity mitogenactivated protein kinase kinase 4 (MP2K4), ectoderm-neural cortex protein 1 (ENC1), and matrix metalloproteinase-27 (MMP27). Specifically, ARPC4 contributes to several physiological processes, including cell migration; abnormally activated cell mobility may eventually result in a metastatic outcome (34). MP2K4 is a member of the MAPK signaling pathway. A report on the deletion and mutation of the $M A P 2 K 4$ gene in breast cancer (35) does not seem to concur with our results on $\mathrm{MBC}$ but suggests the implication of MP2K4 in tumor suppression. ENC1 has been previously detected in breast cancer cell lines, and its expression level 
was higher compared to normal breast epithelial cells; our findings concurs well with this (36). The same authors suggested that ENC1 enhances oxidative stress response in breast cancer cells via the nuclear factor (erythroid-derived 2)-like 2 (NRF2) pathway, identifying an important biological role of this protein. Regarding MMP27, although MMPs were initially identified as markers of poor prognosis for patients with breast cancer, subsequent clinical trials have been disappointing (37). Further research better defined the key role of MMPs as breast cancer promoters, highlighting the importance of these molecules (38).

Concerning the limitations of our study, we need to point out that the number of patients with MBC was small $(n=11)$ due to the low incidence of breast cancer in men (fewer than one per 100,000 men in Europe) $(2,39)$. Despite the small number of patients tested and the potential influence of selection bias, we obtained reproducible results.

In conclusion, our results provide important evidence that there is a differential serum protein expression profile in men with breast cancer compared to healthy individuals. Our studies, therefore, address the need to manage MBC optimally, by showing the feasibility of identifying potential biomarkers associated with MBC using proteomics. This approach may ensure that the treatment of all patients with breast cancer, regardless of their sex, can be accomplished via a personalized approach.

\section{Conflicts of Interest}

The Authors declare that they have no potential conflicts of interest.

\section{References}

1 Massarweh SA and Choi GL: Special considerations in the evaluation and management of breast cancer in men. Curr Probl Cancer 40(2-4): 163-171, 2016

2 Ly D, Forman D, Ferlay J, Brinton LA and Cook MB: An international comparison of male and female breast cancer incidence rates. Int J Cancer 132(8): 1918-1926, 2013.

3 Wang Y, Klijn JG, Zhang Y, Sieuwerts AM, Look MP, Yang F, Talantov D, Timmermans M, Meijer-van Gelder ME, Yu J, Jatkoe T, Berns EM, Atkins D and Foekens JA: Gene-expression profiles to predict distant metastasis of lymph-node-negative primary breast cancer. Lancet 365(9460): 671-679, 2005.

4 Zeidan BA, Townsend PA, Garbis SD, Copson E and Cutress RI: Clinical proteomics and breast cancer. Surgeon 13(5): 271-278, 2015.

5 Alfaro JA, Sinha A, Kislinger $\mathrm{T}$ and Boutros PC: Oncoproteogenomics: cancer proteomics joins forces with genomics. Nat Methods 11(11): 1107-1113, 2014.

6 Shukla HD, Mahmood J and Vujaskovic Z: Integrated proteogenomic approach for early diagnosis and prognosis of cancer. Cancer Lett 369(1): 28-36, 2015.

7 Anderson WF, Jatoi I, Tse J and Rosenberg PS: Male breast cancer: a population-based comparison with female breast cancer. J Clin Oncol 28(2): 232-239, 2010.
8 Losurdo A, Rota S, Gullo G, Masci G, Torrisi R, Bottai G, Zuradelli M, Gatzemeier W and Santoro A: Controversies in clinicopathological characteristics and treatment strategies of male breast cancer: A review of the literature. Crit Rev Oncol Hematol 113: 283-291, 2017.

9 Senkus E, Kyriakides S, Ohno S, Penault-Llorca F, Poortmans P, Rutgers E, Zackrisson S, Cardoso F; ESMO Guidelines Committee. Primary breast cancer: ESMO Clinical Practice Guidelines for diagnosis, treatment and follow-up. Ann Oncol 26(Suppl 5): v8-30, 2015.

10 Vaiopoulou A, Gazouli M, Papadopoulou A, Anagnostopoulos AK, Karamanolis G, Theodoropoulos GE, M'Koma A and Tsangaris GT: Serum protein profiling of adults and children with Crohn disease. J Pediatr Gastroenterol Nutr 60(1): 42-47, 2015.

$11 \mathrm{Li} \mathrm{J}$, Zhang Z, Rosenzweig J, Wang YY and Chan DW: Proteomics and bioinformatics approaches for identification of serum biomarkers to detect breast cancer. Clin Chem 48(8): 1296-304, 2002.

12 Chung L, Moore K, Phillips L, Boyle FM, Marsh DJ and Baxter RC: Novel serum protein biomarker panel revealed by mass spectrometry and its prognostic value in breast cancer. Breast Cancer Res 16(3): R63, 2014.

13 Poste G: Bring on the biomarkers. Nature 468(7329): 156-157, 2011.

14 Chahed K, Kabbage M, Hamrita B, Guillier CL, Trimeche M, Remadi S, Ehret-Sabatier L. and Chouchane L: Detection of protein alterations in male breast cancer using two-dimensional gel electrophoresis and mass spectrometry: the involvement of several pathways in tumorigenesis. Clin Chim Acta 388(1-2): 106-114, 2008.

15 Bonte D, Lindvall C, Liu H, Dykema K, Furge K and Weinreich M: CDC7-DBF4 kinase overexpression in multiple cancers and tumor cell lines is correlated with p53 inactivation. Neoplasia 10(9): 920-a31, 2008.

16 Choschzick M, Lebeau A, Marx AH, Tharun L, Terracciano L, Heilenkötter U, Jaenicke F, Bokemeyer C, Simon R, Sauter G and Schwarz J: Overexpression of cell division cycle 7 homolog is associated with gene amplification frequency in breast cancer. Hum Pathol 41(3): 358-365, 2010.

17 A Study To Evaluate TAK-931 In Participants with Advanced Nonhematologic Tumors - Full Text View - Clinicaltrials.Gov. Clinicaltrials.Gov. 2018. Accessed 11 Nov. 2018. https:// clinicaltrials.gov/ct2/show/NCT02699749.

18 Scatena C, Roncella M, Di Paolo A, Aretini P, Menicagli M, Fanelli G, Marini C, Mazzanti CM, Ghilli M, Sotgia F, Lisanti MP and Naccarato AG: Doxycycline, an inhibitor of mitochondrial biogenesis, effectively reduces cancer stem cells (CSCs) in early breast cancer patients: A clinical pilot study. Front Oncol 8: 452, 2018.

19 Sotgia F, Fiorillo M and Lisanti MP: Mitochondrial markers predict recurrence, metastasis and tamoxifen-resistance in breast cancer patients: Early detection of treatment failure with companion diagnostics. Oncotarget 8(40): 68730-68745, 2017.

20 Sotgia F, Whitaker-Menezes D, Martinez-Outschoorn UE, Salem AF, Tsirigos A, Lamb R, Sneddon S, Hulit J, Howell A and Lisanti MP: Mitochondria "fuel" breast cancer metabolism: Fifteen markers of mitochondrial biogenesis label epithelial cancer cells but are excluded from adjacent stromal cells. Cell Cycle 11(23): 4390-401, 2012. 
21 Chandler PD, Song Y, Lin J, Zhang S, Sesso HD, Mora S, Giovannucci EL, Rexrode KE, Moorthy MV, Li C, Ridker PM, Lee IM, Manson JE, Buring JE and Wang L: Lipid biomarkers and long-term risk of cancer in the Women's Health Study. Am J Clin Nutr 103(6): 1397-407, 2016.

22 Borgquist S, Butt T, Almgren P, Shiffman D, Stocks T, OrhoMelander M, Manjer J and Melander O: Apolipoproteins, lipids and risk of cancer. Int J Cancer 138(11): 2648-2656, 2016.

23 Lin X, Hong S, Huang J, Chen Y, Chen Y and Wu Z: Plasma apolipoprotein $\mathrm{A} 1$ levels at diagnosis are independent prognostic factors in invasive ductal breast cancer. Discov Med 23(127): 247-258, 2017.

24 Opstal-van Winden AW, Krop EJ, Kåredal MH, Gast MC, Lindh $\mathrm{CH}$, Jeppsson MC, Jönsson BA, Grobbee DE, Peeters PH Beijnen JH, van Gils $\mathrm{CH}$ and Vermeulen RC: Searching for early breast cancer biomarkers by serum protein profiling of prediagnostic serum; a nested case-control study. BMC Cancer 11: 381, 2011.

25 Cibeira GH, Giacomazzi J, Aguiar E, Schneider S, Ettrich B, DE Souza CI, Camey S, Caleffi M, Weber B, Ashton-Prolla P and Moriguchi EH: Apolipoprotein E genetic polymorphism, serum lipoprotein levels and breast cancer risk: A case-control study. Mol Clin Oncol 2(6): 1009-1015, 2014.

26 Xu X, Wan J, Yuan L, Ba J, Feng P, Long W, Huang H, Liu P, Cai Y, Liu M, Luo J and Li L: Serum levels of apolipoprotein E correlates with disease progression and poor prognosis in breast cancer. Tumour Biol 37(12): 15959-15966, 2016.

27 Petrik V, Saadoun S, Loosemore A, Hobbs J, Opstad KS, Sheldon J, Tarelli E, Howe FA, Bell BA and Papadopoulos MC: Serum alpha 2-HS glycoprotein predicts survival in patients with glioblastoma. Clin Chem 54(4): 713-22, 2008.

28 Watson K, Koumangoye R, Thompson P, Sakwe AM, Patel T, Pratap S and Ochieng J: Fetuin-A triggers the secretion of a novel set of exosomes in detached tumor cells that mediate their adhesion and spreading. FEBS Lett 586(19): 3458-3463, 2012.

29 Nangami GN, Watson K, Parker-Johnson K, Okereke KO, Sakwe A, Thompson P, Frimpong N and Ochieng J: Fetuin-A ( $\alpha 2 \mathrm{HS}$-glycoprotein) is a serum chemo-attractant that also promotes invasion of tumor cells through Matrigel. Biochem Biophys Res Commun 438(4): 660-665, 2013.

30 Pucci-Minafra I, Di Cara G, Musso R, Cancemi P, Albanese NN, Roz E and Minafra S: Retrospective proteomic screening of 100 breast cancer tissues. Proteomes 5(3): 15, 2017.

31 Cardoso F, Bartlett JMS, Slaets L, van Deurzen CHM, van Leeuwen-Stok E, Porter P, Linderholm B, Hedenfalk I, Schröder C, Martens J, Bayani J, van Asperen C, Murray M, Hudis C, Middleton L, Vermeij J, Punie K, Fraser J, Nowaczyk M, Rubio IT, Aebi S, Kelly C, Ruddy KJ, Winer E, Nilsson C, Dal Lago L, Korde L, Benstead K, Bogler O, Goulioti T, Peric A, Litière $\mathrm{S}$, Aalders $\mathrm{KC}$, Poncet $\mathrm{C}$, Tryfonidis $\mathrm{K}$ and Giordano $\mathrm{SH}$ : Characterization of male breast cancer: results of the EORTC 10085/TBCRC/BIG/NABCG International Male Breast Cancer Program. Ann Oncol 29(2): 405-417, 2018.
32 Zagouri F, Sergentanis TN, Azim HA Jr., Chrysikos D, Dimopoulos MA and Psaltopoulou T: Aromatase inhibitors in male breast cancer: a pooled analysis. Breast Cancer Res Treat 151(1): 141-1467, 2015.

33 Pasqualini JR, Chetrite G, Blacker C, Feinstein MC, Delalonde L, Talbi M and Maloche C: Concentrations of estrone, estradiol, and estrone sulfate and evaluation of sulfatase and aromatase activities in pre- and postmenopausal breast cancer patients. J Clin Endocrinol Metab 81(4): 1460-1464, 1996.

34 Su X, Wang S, Huo Y and Yang C: Short interfering RNAmediated silencing of actin-related protein $2 / 3$ complex subunit 4 inhibits the migration of SW620 human colorectal cancer cells. Oncol Lett 15(3): 2847-2854, 2018.

35 Su GH, Hilgers W, Shekher MC, Tang DJ, Yeo CJ, Hruban RH and Kern SE: Alterations in pancreatic, biliary, and breast carcinomas support MKK4 as a genetically targeted tumor suppressor gene. Cancer Res 58(11): 2339-2342, 1998.

36 Seng S, Avraham HK, Jiang S, Yang S, Sekine M, Kimelman N, $\mathrm{Li} \mathrm{H}$ and Avraham S: The nuclear matrix protein, NRP/B, enhances NRF2-mediated oxidative stress responses in breast cancer cells. Cancer Res 67(18): 8596-8604, 2007.

37 Sparano JA, Bernardo P, Stephenson P, Gradishar WJ, Ingle JN, Zucker S and Davidson NE: Randomized phase III trial of marimastat versus placebo in patients with metastatic breast cancer who have responding or stable disease after first-line chemotherapy: Eastern Cooperative Oncology Group trial E2196. J Clin Oncol 22(23): 4683-4690, 2004

38 Radisky ES and Radisky DC: Matrix metalloproteinases as breast cancer drivers and therapeutic targets. Front Biosci 20: 1144-63, 2015.

39 Ferlay J, Colombet M, Soerjomataram I, Dyba T, Randi G, Bettio M, Gavin A, Visser O and Braya F: Cancer incidence and mortality patterns in Europe: Estimates for 40 countries and 25 major cancers in 2018. Eur J of Cancer 103: 356-387, 2018.
Received December 17, 2018

Revised January 12, 2019

Accepted January 16, 2019 